\title{
O RESTO ERA RISCO
}

JOSÉ RESENDE por RAFAEL VOGT MAIA ROSA

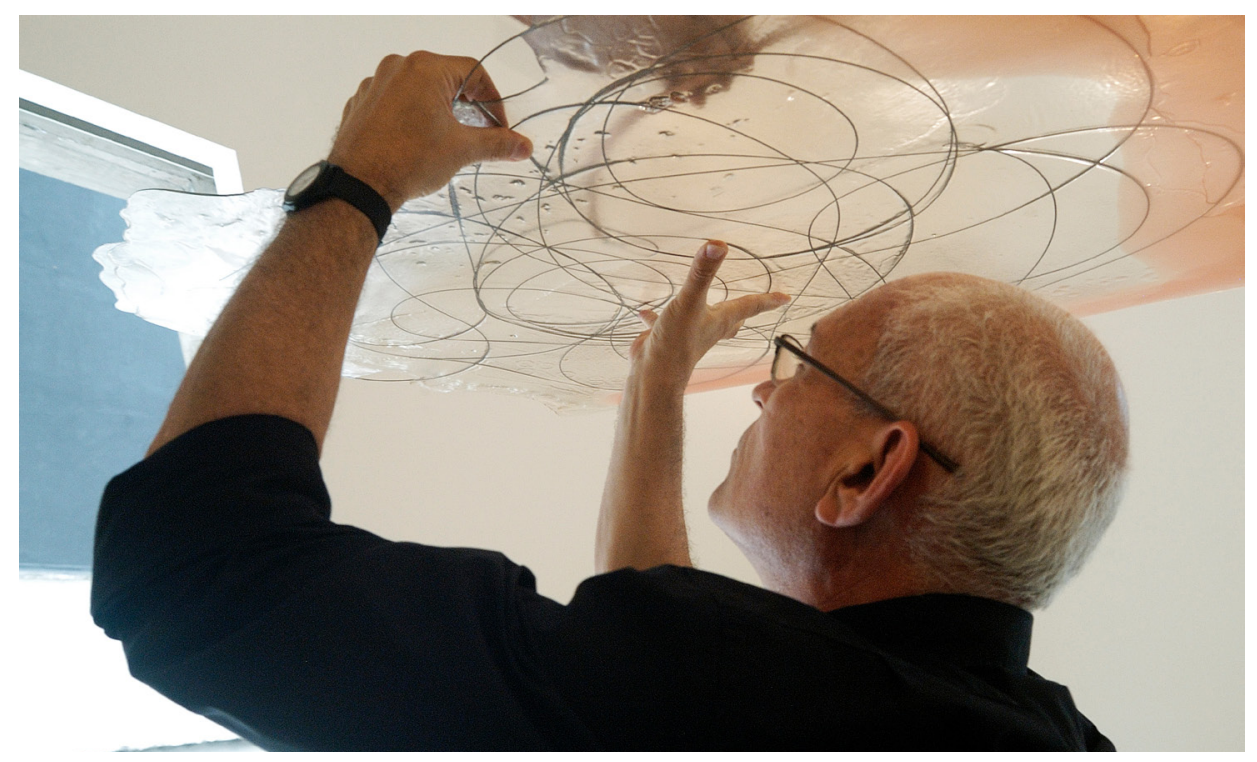

foto: Christiana Carvalho

José Resende (São Paulo, 1945) manteve no desenvolvimento de sua obra uma tridimensionalidade resistente a um processo de transformação que a dissolvesse em outras possibilidades que caracterizaram o momento em que se iniciou nas artes plásticas. O artista, que integrou o grupo Rex nos anos de 1960 e foi um dos mentores da Escola Brasil:, na década seguinte, apesar de ter realizado exposições que estiveram no limite da instalação - e mesmo, como ele diz, "cometido" algumas raras pinturas -, tem o corpo de seu trabalho voltado à escultura. Entretanto, em vez disso poder ser tomado como uma predisposição formalista, parece dizer mais respeito a um aspecto temático de fundo: uma aproximação específica com a figuração e com o corpo. Desde os tempos de seu diálogo com Wesley Duke Lee, quando a prática do desenho representava uma forma de constituição do olhar e uma espécie de "alfabetização visual", Resende já partia para experimentações que engendravam alguma 
figuração, como se brotada de uma predisposição endêmica e, de certa maneira, imune aos deslocamentos associados ao ready-made. Em suas peças, nas quais a matéria se articula de forma explícita e se procura uma escala imprevisível relacionada à presença do espectador, nunca deixa de ocorrer o reconhecimento de uma imagem de certo modo empática, que geralmente acaba trazendo apelidos à sua frequente não intitulação.

$\mathrm{Na}$ entrevista a seguir, o artista fala sobre como esses aspectos estão ligados em seu percurso a uma relação com um tipo de crítica marcada pela proximidade com a gênese do trabalho em sua inserção cultural e, por outro lado, independente de uma conjunção com um fator vivencial, do componente urbano em sua poética e sobre de que modo a experiência com um "ensino" relativamente alternativo e embates com o meio artístico fizeram sua obra reagir de modo independente e deliberadamente avesso à figura emblemática do próprio artista.

Este número da Celeuma é dedicado aos “erros críticos”. Há depoimentos de críticos de várias áreas a respeito de equívocos que tenham cometido em suas trajetórias e depoimentos de artistas a respeito de sua relação com a crítica. Como foi ou é sua relação com esse segmento?

Resende - Eu vejo um momento ímpar entre a geração que me antecede imediatamente, que teve tanto com Mario Pedrosa e Ferreira Gullar uma relação produtiva, entre trabalhos e a questão crítica. Houve um intercâmbio mais internalizado com a questão crítica que colaborou com o desenvolvimento de uma série de artistas. Minha geração teve ainda essa proximidade, centrada principalmente no Ronaldo Brito, e também no Paulo Sergio Duarte, e com aqueles que por seu entusiasmo acabaram se aproximando das artes plásticas, embora não fossem inicialmente ligados a isso, como o Paulo Venâncio, o Rodrigo (Naves), o Beto (Alberto Tassinari), que são, mais ou menos, desdobramentos de um encanto que marca exatamente o momento dessa relação mais íntima com a produção.

\section{Esse “encanto" se refere a quê??}

Resende - O encanto que o Ronaldo de alguma forma exercia como profissional por uma relação tão direta e tão absoluta com a questão 
plástica. Quer dizer, embora seja poeta e desenvolva outras atividades, ele tem uma intimidade com a questão do olho que esses outros críticos têm em um grau muito menor. Isso pode ter a ver com o número de produtores e os desdobramentos que isso teve, mas, seguramente, embora a relação deles fosse próxima com artistas da geração posterior, por exemplo, a Casa 7, ou, enfim, artistas mais jovens, há uma diferença muito grande entre uma relação mais produtiva e próxima à produção de outra relação crítica que é mais julgadora, mais distanciada, que tenta colocar sua posição com diferenças em relação à produção, aderindo a ela, mas com adjetivos, e não de forma internalizada. Talvez a única exceção em que há um diálogo mais denso com a crítica, nesse caso, com uma qualidade muito específica, é o Nuno (Ramos). Quanto aos outros, acho que são acolhidos, mas de uma maneira qualificativa.

\section{E no caso do Nuno, como você pensa que isso ocorre?}

Resende - No diálogo do Nuno isso se aproxima de uma questão mais literária, que permeia todas essas preocupações. Ou até mesmo no caso do Beto (Tassinari), por exemplo, com a questão da filosofia. Há um diálogo que aproxima, mas acho que não tem muito a ver com os processos mais íntimos que o Ronaldo manteve em relação ao meu trabalho, ao do Tunga, do Waltercio (Caldas). E mesmo na recuperação do trabalho e integração grande com o (Eduardo) Sued. Ou seja, mesmo depois de uma mudança para uma preocupação de retornar a produções anteriores sob um prisma de uma visada mais contemporânea, no caso do Sergio Camargo e Iberê Camargo, há um entrosamento entre a escrita do Ronaldo e a produção plástica de uma forma muito mais intensa e integrada, diversa de um distanciamento mais crítico, de dar qualidades e não substância aos trabalhos.

\section{É um elogio claro à troca efetiva entre crítico e artista.}

Resende - Eu acredito que seja o exemplo mais produtivo que se tem, e não sei se é viável hoje, que se reproduza novamente. Porque as especialidades ganharam proporções muito maiores, pois as carreiras profissionais ganharam uma ênfase maior do que suas relações culturais enquanto tal. As relações de poder, de interferência, ganharam um sentido de carreira profissional diversa daquela que anteriormente permitia maior entrosamento entre uma coisa e outra. 
Você acredita, por outro lado, que o artista esteja mais preocupado com essa profissionalização, com o mercado, e que por isso o papel do crítico também tenha se alterado?

Resende - Não só o mercado. A produção teórica ou crítica se transferiu mais para a universidade. Anteriormente, o Ronaldo nunca teve ligação com a universidade, o Mario Pedrosa nunca foi da universidade. Institucionalmente, tudo se profissionalizou. Há um endosso universitário que anteriormente nunca foi considerado, fazendo com que a relação de poder esteja mediada pela universidade. Isso é uma coisa que não existia na própria universidade, nunca houve.

\section{E com quem você acha que o artista está dialogando hoje?}

Resende - Acho que o que acontece neste momento é que o campo das artes plásticas se expandiu de uma maneira brutal e de uma forma muito abrupta. Ou seja, você tem, no início dos anos $80 \ldots$ não que a gente queira dividir a história por décadas, mas, no Brasil, esse período coincide muito com um crescimento de todo um processo de profissionalização e transformação muito grande. É muito diverso, vamos dizer, a concretude de uma carreira profissional como artista a partir dos anos 80 em diante, do que era anteriormente. Tanto que você pode ver que a geração anterior fez galerias, fez revistas, fez escolas... fez, enfim, tudo. Porque nada existia. A partir de 80, você tem um terreno profissional muito mais concreto, trazido pelo mercado, sim, mas trazido também por todas as outras relações que a instituição começa a abarcar; o advento das curadorias, que é outro campo profissional que não é próprio da produção de arte, uma série de atividades que se condensam com um projeto que passa a ser mais de concretização de uma carreira do que propriamente de intervenção cultural. Essa é que eu acho que é a grande diferença. Porque a briga anterior era para fazer reconhecer, legitimar um processo de expressão e manifestação das artes plásticas que estava completamente descaracterizado de qualquer conotação. E isso se estende a outras áreas: a diferença entre um diretor do Cinema Novo e um diretor de hoje que, de certa forma, está envolvido num processo de produção que econômica e institucionalmente tem outro desenho, outra forma.

E a partir desse crescente processo de especialização, o que você diria 
que qualifica ou distingue as artes plásticas de outras expressões? Resende - Se você pensar no trabalho do Wesley (Duke Lee), que foi por onde nós entramos, já há uma provocação nesse sentido. Quer dizer, a primeira obra que eu expus foi o "Bonecão" (Homenagem ao Horizonte Longínquo, realizada em 1967, que dialoga diretamente com experimentos espaciais pouco ortodoxos de Duke Lee). Eu nunca expus desenho. "Cometi" pinturas, mas foi sempre uma relação de diversificar mais do que de especializar.

Agora, mais especificamente em sua produção, como vê a relação com o corpo e com a figuração?

Resende - No meu trabalho, a relação com o corpo sempre esteve vinculada a uma tensão com a situação de escala dele com quem o vê. E não só no dimensionamento e em uma provocação que ele ocasiona, mas também na possibilidade da construção, de ela ser o mais declarada possível para que haja um entendimento de como foi produzida. Uma certa figuração, vamos dizer assim, no sentido da evocação de uma imagem que se torna caracterizável pelo trabalho sempre foi uma espécie de critério. Ou seja, o trabalho sempre teve uma visualidade que lhe dá uma unicidade. Tanto que a maior parte das minhas obras não tem título e, no entanto, eu consigo de alguma forma que você possa ter uma referência que vem através da imagem delas.

Nesse sentido parece que seu trabalho tem um desenvolvimento em que a gente não encontra muitas rupturas. E não se vê, no seu percurso, um momento em que a apropriação ou o gesto intelectual substituía a produção de fato.

Resende - A condição foi sempre anticonceitual porque qualquer relação que o trabalho tenha buscado foi a partir da sua necessidade de confronto com a presença dele. Se não for isso, ele não subsiste. Eu me lembro de uma conversa com a Mira (Schendel), quando fiz uma exposição que tinha umas lâminas de vidro encostadas na parede, e ela dizia “se eu for ao vidraceiro não tem nada, eu chego aqui e tem." Então há uma diferença que eu acho que é muito própria. O deslocamento, a ideia que isso possa ter, necessita de uma relação da presença da coisa como provocadora do seu sentido, por mais conceitual que seja a justificativa para se fazer esse deslocamento. Tanto que a questão dos 
materiais, no meu caso, não vem de uma questão artesanal de produção escultórica, mas de uma ideia de construção, de agregar coisas. A submissão dos materiais ao trabalho é absoluta. E pode-se dizer, por paradoxo, que no meu trabalho o menos significativo sejam os materiais, embora você encontre nele uma diversidade muito grande de qualidades de materiais utilizados. Mas é através de uma recolocação daquilo em outra situação que o trabalho é gerado. Podem ser até os vagões (referência à obra realizada com vagões de trem suspensos, em 2001). Os vagões estão lá, mas o vagão em si não é a questão, seria o inverso de você, vamos dizer assim, dar, no momento da escolha, um caráter conceitual. É o inverso porque aquilo só se torna uma atitude que remete à paisagem, que remete às ideias e aos conceitos, na hora em que o material subverte uma relação que é cotidiana, normal, de um material que não tem significado nenhum, até que essa transformação dote-o de um outro sentido.

\section{Mas há aí também uma relação talvez com a arquitetura e com a natureza. \\ Resende - Há uma relação com um repertório de elementos que são articulados na questão urbana, estão na sua vivência da urbanidade: é a folha de vidro, o cano, o cobre, enfim, são elementos que têm essa tensão em relação à cidade.}

\section{A propósito disso eu queria lhe mostrar uma imagem (trabalho depredado, instalado em 1979, na Praça da Sé, em São Paulo). O que dizer do processo que levou da idealização e realização desse trabalho ao momento atual, em que ele é literalmente consumido por sua condição urbana?}

Resende - Eu acho que não é o meu trabalho particularmente. Aquela situação que ali se constituiu é uma relação muito pouco resolvida. Em contraponto a isso, você pode pensar na Vênus (trabalho de 1991) lá no Rio, que tem um uso, que é substituída de tanto em tanto porque o pessoal do skate às vezes interfere, mas é uma peça que nunca foi pichada, nunca foi desvirtuada.

Ou o Passante (trabalho de 1995), no Rio também.

Resende - O Passante também, por ele se autodefender melhor, por ser 
muito alto... Então o que acontece ao nível do chão não mexe muito.

$E$ isso poderia ser atribuído ainda ao fato de essas duas últimas obras que você mencionou, no Rio, serem "figurativas"?

Resende - Não acho que seja. Mas de qualquer maneira há uma relação de maior proximidade que o trabalho acaba constituindo e que trouxe um viés para que isso tivesse uma diferenciação das outras coisas que não são tão bem tratadas no convívio. O problema aí não é da arte, mas do convívio.

\section{Em depoimento sobre a Maria Martins, você falou no elemento} libidinal como fator de conexão da sua poética com a dela. Você vê esse teor mais "natural”, digamos, esse impulso como algo menos articulado, que extrapola o componente cultural da urbanidade? Resende - Olha, o que eu posso antepor ao que você está dizendo, e é quase uma piada, mas aconteceu e foi fotografado - devia ter sido filmado. Eu expus, em 1982, um trabalho no IAB de São Paulo, era aquele de borracha com tubos vermelhos se debatendo sobre aquele negócio e isso foi inaugurado às sete horas da noite, na General Jardim, no meio de todos os inferninhos que ali estavam. Então o público que aderiu àquilo achou um sentido imediatamente, não teve dúvida e ficou ali assistindo como se fosse um espetáculo pornô, explícito. Então eu acho que essa questão não passa tão ao largo da cidade. Eu estou pensando no que você me perguntou sobre se o trabalho era mais "figurativo". O fato de a negona ter um movimento, se movimentar e acabar sambando, no Rio de Janeiro, tem um sentido, sim, que vai além da coisa da figura, vai da condição que a rua de alguma forma acrescenta a ela. Ali ela motiva de alguma forma a coisa da dança. Ao mesmo tempo, se você pensar essa coisa de as pessoas jogarem pedras e tirarem um som de meu trabalho no Parque do Ibirapuera, é algo que acrescenta um sentido que é a relação da obra com onde ela está. Eu não diria que seja a origem do trabalho, mas, de alguma maneira, a perspectiva dessa interação é possível, não é descartada, e não é conceitual.

Você teve um acidente de carro que alterou sua visão. Essa situação traumática teve ressonância na sua poética?

Resende - Na época eu não permitia absolutamente que afetasse. A 
situação imediatamente posterior foi até uma reação impedindo que isso tivesse algum sentido. O que mais me alarmava no momento, e que logo se desfez, era que você, perdendo a acuidade de uma das visões, você perde profundidade, e eu pensei que pudesse alterar o entendimento da montagem de uma exposição. E isso eu não tinha ainda experimentado quando fui fazer uma mostra em Hartford, nos EUA. Tanto que eu fui com o (Carlos) Fajardo para me apoiar se a coisa ficasse complicada, e de fato foi ótimo, uma força que ele me deu... Mas isso se resolveu porque são certas circunstâncias de luz e contraluz que na verdade você não perde tanto.

\section{E se arriscar em nome de uma aproximação deliberada entre vida pessoal e atividade artística?}

Resende - Em relação ao trabalho houve sempre riscos assumidos que foram levados para sua produção, sem grandes temores. Acho que o trabalho nunca teve nenhum resguardo meu de assumir riscos com ele, desde sempre. Eu estava fazendo coisas cujo entendimento eu tinha muito relativamente, algo acontecendo ali... O resto era risco. Agora, essa relação "arte-vida" de alguma maneira ocorreu ao contrário do que você me pergunta. A expectativa que se tinha, também no caso de pessoas com as quais eu estive junto - umas mais, outras menos -, a identidade maior ocorreu com aquelas com as quais você se surpreendia exatamente por não corresponderem ao que seria a figura do artista. E nisso eu sempre fui muito rigoroso. Eu nunca tive cara de artista. Ao contrário, a surpresa sempre veio a meu favor por eu não ser identificado como tal. Se você tiver que colocar uma atividade em que mais intrinsecamente as duas coisas estejam relacionadas, trabalho e vida, essa aproximação não vai caracterizar o grupo com o qual eu estaria mais identificado. Os riscos nunca vieram provocados por um desafio de vida. Eu não sou aventureiro, eu não criei situações-limite para qualquer experimento que fosse incorporado ao trabalho, mas também nunca tive preconceito com quem tivesse. $\mathrm{O}$ fato é que tive contato e identidade com artistas, companheiros muito próximos como o Tunga e o Waltercio (Caldas) dos dois eu nunca me desliguei -, embora a relação com o trabalho venha de uma maneira simetricamente oposta entre vida e obra. Já em outros casos, há questões de vida mais configuradas no trabalho, mas mesmo o Wesley e o Paulo Mendes da Rocha, que foram balizas na minha 
formação, são pessoas muito diversas, um muito mais aventureiro que o outro, enfim...

E no caso da Mira Schendel, que me parecer uma pessoa importante no seu processo?

Resende - A Mira teve um percurso muito intelectual, e eu creio que as relações de vida eram muito comedidas - com suas idiossincrasias. E se você quiser, a rigor, por mais próxima que seja identificada com o Parangolé, toda a questão homossexual do Oiticica não configura. Não houve muito essa proximidade. Para nós, uma Marina Abramovic, por exemplo, é uma situação que não se colocava. E isso tudo, resumindo, é impossível, essa relação nesse teor de confronto, se as condições culturais nas quais você está inserido são tão frágeis, tão pouco constituídas. Quer dizer: como é que você vai trazer uma relação para a arte, quando a própria arte não se configura como uma questão de vida estável?

\section{Você diria que o impacto da produção artística no meio cultural é menor hoje?}

Resende - Olha... eu acredito que houve um esvaziamento considerável. Isso não se dá pela quantidade ou qualidade que a produção tem hoje, mas é uma relação muito menos ambiciosa. O que decaiu foi o inimigo... Há mais conciliação, menos atrito e menos ambição. A necessidade anterior gerava uma atividade real e concreta para quem produzia. Você tinha que, de alguma forma, conquistar não só o trabalho, mas também o lugar do trabalho.

\section{Você gostaria de ter realizado mais trabalhos públicos?}

Resende - Existe uma série de projetos que teriam que ser reintegrados à forma como foram propostos, uma efetivação da qual eu não tenho retorno. As condições com as quais eu acabei contando foram muito ocasionais; foram ótimas, mas não garantem uma continuidade. Ter trabalhado com os vagões foi maravilhoso, só que acabou em três meses. No Sul, em Porto Alegre (referência à obra Olhos Atentos, de 2005), ficou uma peça integrada, mas, de repente, resolveram cortar um pedaço dela e acabou-se a história dela. A peça da USP (referência à obra de 1997), apesar de ser da Poli, puseram lá uma bengala em torno dela, mudaram de lugar, quer dizer, ela não existe mais. Então existem esses trabalhos 
que, embora tenham existido com uma certa intenção, hoje nem existem mais. A perspectiva de outros trabalhos depende de condições muito complexas, institucionalmente muito complicadas... Mas é o que traria uma expectativa para a qual o trabalho aponta, que é experimentar com mais efetividade uma escala que ele deveria ter, ou seja, essa questão que não é relativa ao tamanho, mas à troca que aquilo pode gerar num campo mais protegido culturalmente, mas também num campo menos protegido, como no caso dos trabalhos no MAM do Rio, que, mais do que uma exposição, restabeleceram um diálogo com um edifício que era uma referência (menção à exposição do artista realizada em 2011). Ou seja, não necessariamente precisa ser um trabalho em local público.

\section{Para terminar, eu gostaria de lhe fazer uma pergunta a respeito do ensino de arte. Na Escola Brasil: havia, no caderno de apresentação, uma frase: “Arte não se ensina, se apreende”. O que você pensa sobre essa atividade?}

Resende - Eu sempre me bati pelo fato de que a Escola Brasil:, mais que uma escola, fosse um centro que se chamava "centro de experimentação artística". Porque uma das perspectivas que a escola gerou, como instituição, foi uma alternativa de desenvolvimento de trabalho com um ganho que viabilizasse sua existência. Ou seja, que você não precisasse ganhar a respeitabilidade do trabalho a partir dos processos mais plausíveis, que naquele momento eram os salões, a Bienal etc. $\mathrm{E}$ sintomaticamente a gente abriu a escola depois de termos participado de salões e tudo o mais, e queríamos fechar esse ciclo e abrir um outro, porque aquele era muito pouco promissor. Então a escola teve sucesso, por um lado, durante quatro anos ela foi economicamente viável, mas em termos de núcleo, como "centro de experimentação", aglutinou muito pouca gente. Ficou muito ilhada em relação a quem mexia e produzia arte. Porque mesmo a geração mais próxima, da Rex, não foi presente na Escola Brasil:. Houve um dinamismo através dela e, no momento em que nós mesmos resolvemos ir para fora, a escola sentiu. Então foi um processo que ficou truncado. Por outro lado, não posso deixar de reconhecer que a escola garantiu a possibilidade que me foi aberta para minha primeira individual, expor no MASP.

\section{Possibilitou em que sentido?}


Resende - Institucional, de você ter prestígio. Eu fui ao (Pietro Maria) Bardi e ele me abriu as portas e eu fiz. Um processo que a escola deveria ter viabilizado para todos, não só para mim. E por conta de uma matéria que o Ronaldo (Brito) veio a fazer sobre essa minha exposição é que eu iniciei uma conversa com ele, do que saiu a revista Malasartes... E eu não conhecia o Waltercio - ninguém, até ali.

\section{E em relação ao livro The Natural way to draw (traduzido no Brasil como Desenhando com o lado direito do cérebro), de Betty Edwards, que o Wesley Duke Lee teria introduzido e que teria sido aplicado na Escola, como você vê, por exemplo, a ideia de que todo um vício estilístico da Escola Brasil: tenha passado por aí?}

Resende - Primeiro que acho que há um mal-entendido, nem tanto em relação ao Wesley, que era um desenhista de grande habilidade, mas ao processo dessa forma de experimentar o risco e a produção gráfica que dele resulta. Porque a razão dessa prática não é pelo que você faz, mas pelo que você se surpreende de que seu olho seja capaz de ver. Ou seja, é o contrário: não é pelo efeito do que é desenhado, mas pelo fato de que você, olhando lá e trançando aqui, de repente traz uma profundidade que se estiver tentando "copiar" você tem menos. Assim, é uma possibilidade, um artifício não para desenhar, mas para você ver que seu olho vê. Então a técnica que o Wesley de alguma forma aplicava não era para você desenhar, era para você ver arte, para você ver o mundo, você acreditar mais no seu próprio olho. E ele era uma pessoa que cultuava isso, era muito verdadeiro e concreto, até porque talvez fosse a pessoa que eu conheci que maior erudição tinha através do olho. Se você conversasse sobre qualquer assunto por meio da palavra, era muito difícil ele ter clareza sobre a história, sobre os conceitos, e ele era uma pessoa informada... Mas era muito menos informada do que na hora em que lembrava uma coisa e abria algo da estante dele na página exata e dizia “era isto aqui que eu queria te dizer". Ele tinha uma memória visual invejável, algo que trouxe sempre a especialidade intelectual que ele tinha.

São Paulo, 31 de julho, 2013 